\title{
EXCESS WINTER MORTALITY OF ROMA POPULATION IN SERBIA, 1992-2007
}

\author{
Ljiljana M. Blagojević1, Dragan C. Bogdanović2, Sladjana J. Jović3 ${ }^{3}$ Zoran G. Milošević ${ }^{3}$, Zana Ć. Dolićanin ${ }^{2}$ \\ ${ }^{1}$ Faculty of Occupational Safety, University of Niš, Serbia \\ 2Department for Biochemical and Medical Sciences, The State University of Novi Pazar, Serbia \\ ${ }^{3}$ Faculty of Medicine, University of Niš, Serbia
}

\section{SUMMARY}

Objectives: Seasonal fluctuations in mortality are associated with age, outdoor temperature, influenza, health care provision, lifestyle risk factors and economic factors. In the Republic of Serbia almost one half of the Roma population lives in poverty and their housing conditions are very poor. The aim of this paper is to describe and compare excess winter mortality (EWM) in Roma and non-Roma population in Serbia from 1992 to 2007.

Methods: Using the national mortality database, this study compares EWM index and rates in Roma and general populations in Serbia. Mean winter temperature and ethnicity are analysed against the results for relative EWM by multiple linear regression adjusted for age.

Results: Frequency analysis showed that Roma population had significantly higher EWM rate per 10,000 (129.2 vs. 76.6) for all causes, all respiratory diseases (26.5 vs. 8.0), and chronic lower respiratory diseases (23.0 vs. 5.2 ) in comparison to non-Roma population. Influenza and pneumonia related deaths represented a small proportion of EWM in both populations. Cardiovascular EWM rate was slightly higher among non-Roma population. Regression analysis demonstrates that Roma ethnicity was associated with significant increase of respiratory EWM rate (regression coefficient $(B)=1.49 ; 95 \% \mathrm{Cl}$ : 0.45-2.54). There was no relationship between ethnicity and cardiovascular and all causes EWM rates.

Conclusions: Although both Roma and non-Roma populations in Serbia suffer from very high rates of excess winter mortality, Roma are significantly more vulnerable. EWM rate from chronic lower respiratory diseases is more than four times higher among Roma people and suggests that they represent one of the most important health problems in Roma population in Serbia.

Key words: Roma population, winter, mortality, respiratory diseases, housing conditions

Address for correspondence: D. C. Bogdanović, Velikotrnavska 9/13, 18000 Niš, Serbia. E-mail: draganbogdanovic@gmail.com

\section{INTRODUCTION}

Excess winter mortality (EWM) is a well-reported phenomenon throughout the world, and most countries suffer from $5 \%$ to $30 \%$ EWM (1). There is an ample literature analysing factors that have been linked with seasonal variations in mortality (2-7). Besides outdoor temperature, older age and other factors, socioeconomic indicators of well-being were found associated with cross country levels of EWM. However, studies within a single country have failed to show any strong link between socioeconomic deprivation and winter mortality.

The Roma population is among the most imperiled groups and is potentially the most vulnerable group in Serbia. According to the most recent 2002 Population Census 108,193 or 1.44\% residents declared themselves as Roma. The majority of Roma people live in settlements near urban centers in Southern Serbia $(37,879)$ and Vojvodina $(29,057)$ and in Belgrade $(19,191)$.

Surveys conducted in Serbia showed significant differences in living conditions between Roma and non-Roma population. In 2007 , almost one half of the Roma population (49.2\%) was poor, which is 9.1 times higher rate than in the general population $5.4 \%$ (8). Notwithstanding such a high percentage of the poor, there were $6.4 \%$ of extremely poor Roma in comparison to $0.1 \%$ in general population. However, it should be taken into account that Roma from Roma settlements, who are potentially most severely affected groups, have not been covered by the survey.
Housing conditions of Roma people are unfavourable (9). They live in crammed houses with more than three people per room or less than $6 \mathrm{sq} \mathrm{m}$ per person. Living conditions as such are 13 times more frequent than in general population $(40 \%$ vs. $3 \%)$. As much as $11 \%$ of households of Roma settlements live in dwellings unfit for living in comparison to $1 \%$ in the general population. The electric power supply is available for only $87 \%$ of Roma households vs. $99.9 \%$ of general population households, $61 \%$ vs. $90 \%$ of households have access to adequate water supply and $32 \%$ vs. $62 \%$ are connected to the sewage system.

Although the vaccination coverage in general population in Serbia reaches $98-100 \%$, twenty nine percent of Roma children 18-29 months of age do not even have vaccination cards (10).

In 2007, about 35 percent of the general population and 25 percent of Roma people used health services in health institutions (outpatient health services in the month preceding the study, and hospital treatment in the preceding 12 months). About $80 \%$ of the general population and $66 \%$ of Roma people with chronic diseases used health services (8).

In 2005 , the mean age of death was $56.83 \pm 18.66$ years in Roma males and $61.97 \pm 19.48$ in Roma females, and it was 12 years lower compared to non-Roma population. In relation to the general population, respiratory system diseases were denoted as the main cause of death (7\% vs. $4 \%)(11)$.

This paper hypothesizes a link between socio-economic deprivation of the Roma population in Serbia and EWM. 


\section{METHODS}

Daily mean temperatures in Belgrade from 1992 to 2007 were obtained from the Republic Hydrometeorological Service.

Daily mortality database for the same period was supplied by the Statistical Office of the Republic of Serbia. The ethnicity information is obligatory in death certificates in Serbia and there was no missing data. However, only in 16,705 of total $1,531,898$ death cases $(1.09 \%)$, ethnicity was coded as unknown.

Causes of death were analysed according to the 10th revision of the International Classification of Diseases. We separately considered deaths from all non-accidental causes (A00-R99), cardiovascular diseases (I00-I99), respiratory diseases (J00$\mathrm{J} 99$ ), influenza (J10 and J11), pneumonia (J12-J18) and chronic lower respiratory diseases (J40-J47). Some $71 \%$ of Roma and $65 \%$ of non-Roma people died at home, so we also separately considered symptoms, signs and abnormal clinical and laboratory findings not classified elsewhere (practically not coded causes: R00-R99).

The number of excess winter deaths is defined as the difference between the number of deaths which occurred during the winter months from December to March (observed winter deaths) and the average number of deaths recorded in the preceding August to November. The number of deaths reported from April to July are used for calculation of expected winter deaths. The EWM index was estimated as the difference between observed winter deaths and expected winter deaths, all divided by expected winter deaths. We also calculated EWM per 10,000 population rates, crude for four broad age bands $(0-44,45-64,65-74$ and 75 years and above), and standardized for the whole population in relation to the European standard population. To compare standardized EWM rates Mantel-Haenszel Chi-square test was performed using Statcalc software from EpiInfo Version 6.0 package (CDC, Washington D.C, Maryland, USA).

Mean winter measurements of environmental temperature and ethnicity are analysed against the results for relative EWM by multiple linear regression, adjusted for age, with ethnicity as categorical explanatory variable and mean winter temperature as an interval-scaled covariate, using R: A language and environment for statistical computing, version 2.2.1. (R Foundation for Statistical Computing, Vienna, Austria).

\section{RESULTS}

Serbia has a moderate-continental climate, with cold winters and hot summers. During the 1992-2007 period, mean daily summer temperature in Belgrade ranged from $9.9^{\circ} \mathrm{C}$ (September 5th 2007 ) to $34.6^{\circ} \mathrm{C}$ (July 22th 2007) with average value of $22.1^{\circ} \mathrm{C}$. Winter mean daily temperature ranged from $-11.5^{\circ} \mathrm{C}$ (December 24th 1999) to $19.1^{\circ} \mathrm{C}$ (March 17th 2001) with average value of $3.4^{\circ} \mathrm{C}$.

Figure 1 indicates a statistically insignificant increase in winter, spring/summer and autumn deaths among Roma population and in winter deaths among non-Roma population over the observed time period. There is a significant increase in autumn and spring/ summer deaths among non-Roma population (linear regression: 354 deaths per year, $95 \% \mathrm{CI}: 306-402, \mathrm{p}<0.001$ and 288 deaths per year, 95\% CI: 208-368, $<<0.001$, respectively), resulting from population ageing in Serbia.

The results show that, between 1992 and 2007, Roma population had significantly higher seasonal variation in mortality (Chi square $=13.26$ and $\mathrm{p}<0.001)$, with an EWM index of $24 \%(95 \%$ CI: 9-39\%), and EWM rate of 129.2 per 10,000 while EWM index and rate in general population were $18 \%$ (95\% CI: $8-28 \%)$ and 76.6 per 10,000 (Table 1 ).

The highest seasonal variation in mortality among Roma was due to respiratory diseases, with a winter increase of some $62 \%$ (95\% CI: 39-85\%) above the average mortality. EWM rate per 10,000 was 26.5 vs. 8.0 among non-Roma (Chi square $=9.55$ and $\mathrm{p}=0.002$ ).

Paradoxically, influenza and pneumonia related deaths represented a small proportion of EWM. On the other hand, chronic lower respiratory diseases account for $83 \%$ respiratory EWM among Roma and 77\% among non-Roma people. EWM index and EWM rate per 10,000 for chronic lower respiratory diseases were $68 \%$ (95\% CI: $37-99 \%$ ) and 23.0 among Roma vs. 55\% (95\% CI: 40-70\%) and 5.2 among non-Roma people (Chi square $=11.59$ and $\mathrm{p}<0.001)$.

EWM index and rate per 10,000 with an underlying cause of cardiovascular disease were slightly higher among non-Roma population. Symptoms, signs and abnormal clinical and laboratory findings not classified elsewhere were noted as causes of deaths in $11.9 \%$ EWM among Roma and $8.6 \%$ among non-Roma
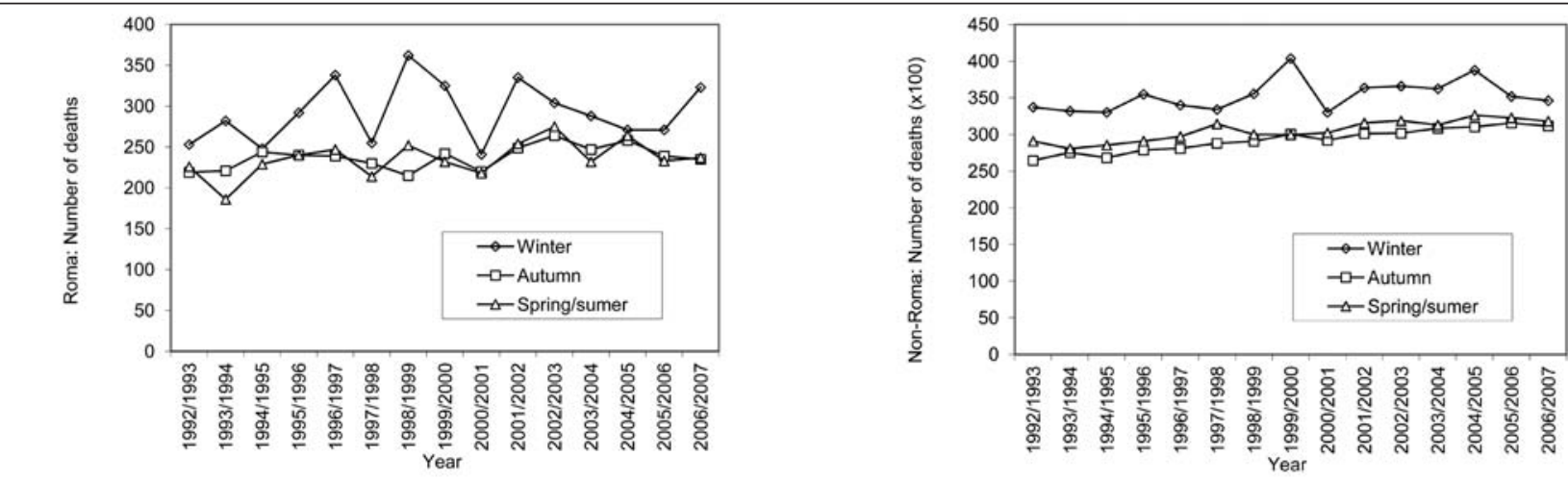

Fig. 1. Winter (diamonds), autumn (squares) and spring/summer (triangles) deaths by year among Roma (left) and non-Roma people (right). 
Table 1. Excess winter mortality by ethnicity, age group and cause of death, Serbia, 1992/1993 to 2006/2007

\begin{tabular}{|c|c|c|c|c|c|c|c|c|c|c|}
\hline \multirow{2}{*}{ Cause of death } & \multicolumn{4}{|c|}{ Roma } & & \multicolumn{5}{|c|}{ non-Roma } \\
\hline & $0-44$ & $45-64$ & $65-74$ & $75+$ & All ages & $0-44$ & $45-64$ & $65-74$ & $75+$ & All ages \\
\hline \multicolumn{11}{|l|}{ Respiratory diseases } \\
\hline Excess winter deaths & 21 & 59 & 63 & 30 & 172 & 194 & 1200 & 3155 & 3890 & 8439 \\
\hline EWM index & 0.55 & 0.51 & 0.73 & 0.75 & 0.62 & 0.31 & 0.42 & 0.56 & 0.55 & 0.52 \\
\hline EWM rate per 10000 & 2.4 & 34.2 & 175.3 & 101.9 & $26.5^{\star}$ & 0.5 & 6.0 & 37.4 & 88.8 & 8.0 \\
\hline \multicolumn{11}{|c|}{ Influenza and pneumonia } \\
\hline Excess winter deaths & 8 & -1 & 2 & 2 & 11 & 192 & 238 & 496 & 1180 & 2106 \\
\hline EWM index & 0.35 & -0.07 & 0.33 & 0.67 & 0.29 & 0.58 & 0.52 & 0.65 & 0.83 & 0.71 \\
\hline EWM rate per 10000 & 0.9 & -0.3 & 5.6 & 6.9 & 1.2 & 0.5 & 1.2 & 5.9 & 26.9 & 1.8 \\
\hline \multicolumn{11}{|c|}{ Chronic lower respiratory diseases } \\
\hline Excess winter deaths & 4 & 61 & 53 & 26 & 143 & 10 & 837 & 2355 & 2422 & 5623 \\
\hline EWM index & 0.30 & 0.64 & 0.73 & 0.81 & 0.68 & 0.07 & 0.48 & 0.60 & 0.54 & 0.55 \\
\hline EWM rate per 10000 & 0.4 & 35.4 & 147.5 & 89.8 & $23.0 \dagger$ & 0.02 & 4.2 & 27.9 & 55.3 & 5.2 \\
\hline \multicolumn{11}{|c|}{ Cardiovascular diseases } \\
\hline Excess winter deaths & 6 & 19 & 88 & 37 & 149 & 262 & 2777 & 7423 & 16917 & 27379 \\
\hline EWM index & 0.12 & 0.06 & 0.30 & 0.19 & 0.18 & 0.12 & 0.13 & 0.17 & 0.24 & 0.20 \\
\hline EWM rate per 10000 & 0.6 & 10.8 & 244.8 & 127.8 & 25.4 & 0.6 & 13.8 & 87.9 & 386.4 & 25.5 \\
\hline \multicolumn{11}{|c|}{ Symptoms, signs and abnormal clinical and laboratory findings, not elsewhere classified } \\
\hline Excess winter deaths & 7 & 33 & 16 & 44 & 100 & 140 & 763 & 1630 & 4502 & 7034 \\
\hline EWM index & 0.06 & 0.23 & 0.20 & 0.73 & 0.25 & 0.05 & 0.10 & 0.21 & 0.28 & 0.20 \\
\hline EWM rate per 10000 & 0.8 & 19.3 & 44.5 & 151.9 & 14.5 & 0.3 & 3.8 & 19.3 & 102.8 & 6.6 \\
\hline \multicolumn{11}{|c|}{ Total nontraumatic mortality } \\
\hline Excess winter deaths & 78 & 224 & 283 & 257 & 841 & 886 & 10263 & 23770 & 46834 & 81752 \\
\hline EWM index & 0.15 & 0.16 & 0.27 & 0.44 & 0.24 & 0.05 & 0.11 & 0.17 & 0.24 & 0.18 \\
\hline EWM rate per 10000 & 9.2 & 131.1 & 786.0 & 887.4 & $129.2 \dagger$ & 2.2 & 51.1 & 281.6 & 1069.6 & 76.6 \\
\hline
\end{tabular}

${ }^{*} p<0.01, \dagger p<0.001$ in comparison with non-Roma.

Table 2. Multiple regression analysis of excess winter deaths, Serbia, 1992/1993 to 2006/2007, adjusted for age

\begin{tabular}{|l|c|c|}
\hline Variable & Coefficient $(95 \% \mathrm{Cl})$ & $p$ \\
\hline Cardiovascular mortality & $-0.50(-2.09$ to 1.09$)$ & 0.53 \\
\hline Temperature (per C) & $-0.87(-3.68$ to 1.94$)$ & 0.54 \\
\hline Roma ethnicity & $-0.15(-0.74$ to 0.43$)$ & 0.61 \\
\hline Respiratory mortality & $1.49(0.45$ to 2.54$)$ & 0.006 \\
\hline Temperature (per C) & $-0.51(-2.69$ to 1.67$)$ & 0.65 \\
\hline Roma ethnicity & $3.42(-0.44$ to 7.28$)$ & 0.08 \\
\hline Total nontraumatic mortality & \\
\hline Temperature (per C) &
\end{tabular}

population. EWM index and rate with those practically not coded causes were higher among Roma, however, it was not significant.

Relative excess winter mortality increased by age in both populations, except for influenza and cardiovascular diseases related
EWM among Roma, and influenza and chronic lower respiratory diseases related EWM among non-Roma people.

Multiple linear regression demonstrates that the mean winter environmental temperature is not found to be associated with EWM rate per 10,000 in Serbia (Table 2). However, Roma ethnicity is found to be associated with significant increase of respiratory EWM rate ( $\mathrm{B}=1.49 ; 95 \% \mathrm{CI}: 0.45-2.54)$. The results of the study indicate no relationship between ethnicity and cardiovascular EWM rate, and a statistically insignificant relationship between ethnicity and all causes EWM rate $(p=0.08)$.

\section{DISCUSSION}

The results show that both Roma and non-Roma populations in Serbia suffer from very high rates of excess winter mortality in comparison with other European countries. Study in 14 European Union countries (1) using data from 1988 to 1997, found that Portugal suffers from the highest rates of excess winter mortality (28\%) followed jointly by Spain (21\%), Ireland (21\%), United Kingdom (18\%) and Greece (18\%), while northern European countries are relatively unaffected by the problem. The strong, 
positive relation with environmental temperature and strong negative relation with thermal efficiency indicate that housing standards in southern and western Europe may play a vital role in seasonal variations of excess winter mortality.

Multiple linear regression analysis showed a trend towards higher mortality in colder winters, but this association was weak and statistically insignificant. The fact that the association between outdoor temperature and daily mortality is not linear but "U shaped" may be the reason why the temperature was not found to be associated with EWM rate.

While both Roma and non-Roma people exhibit similar rate of EWM from cardiovascular diseases, EWM rate from chronic lower respiratory diseases among Roma is more than four times higher. Such results suggest that chronic lower respiratory diseases represent one of the most important health problems in Roma population in Serbia. Elimination or control of the well-known modifiable risk factors associated with asthma, chronic bronchitis and emphysema (12-16) could be the key factor in EWM reduction among Roma population in Serbia.

There are several limitations in our research. Many members of Roma population do not have legal documents and it is likely that they are not registered by population censuses. It is also possible that, to avoid stigmatization, some of them did not declare Roma heritage to census takers, or Roma heritage of their deceased family members to death certificate issuing officials. All of this could bias the research. Despite limitations, this research gives valuable insight into the health problems of Roma population in Serbia, and the foundation for future research.

\section{Acknowledgements}

The study was supported by the Ministry of Science and Technological Development of the Republic of Serbia (project no. 44004 and project no. 175061).

\section{REFERENCES}

1. Healy JD. Excess winter mortality in Europe: a cross country analysis identifying key risk factors. J Epidemiol Community Health. 2003 Oct;57(10):784-9.
2. Laake K, Sverre JM. Winter excess mortality: a comparison between Norway and England plus Wales. Age Ageing. 1996 Sep;25(5):343-8.

3. Clinch JP, Healy JD. Housing standards and excess winter mortality. J Epidemiol Community Health. 2000 Sep;54(9):719-20.

4. Barnard LF, Baker MG, Hales S, Howden-Chapman PL. Excess winter morbidity and mortality: do housing and socio-economic status have an effect? Rev Environ Health. 2008 Jul-Sep;23(3):203-21.

5. Lawlor DA, Maxwell R, Wheeler BW. Rurality, deprivation, and excess winter mortality: an ecological study. J Epidemiol Community Health. 2002 May;56(5):373-4.

6. Ferriman A. Excess winter deaths linked to temperatures in cold homes. BMJ. 2001 Nov 24;323(7323):1207.

7. Aylin P, Morris S, Wakefield J, Grossinho A, Jarup L, Elliott P. Temperature, housing, deprivation and their relationship to excess winter mortality in Great Britain, 1986-1996. Int J Epidemiol. 2001 Oct;30(5):1100-8.

8. Statistical Office of the Republic of Serbia. Living standards measurements study, Serbia 2002-2007. Belgrade: Statistical Office of the Republic of Serbia; 2008.

9. Bjeloglav D, David H, Krstic G, Matkovic G. LSMS Project 2002-2003: Life in Serbia through the survey data. Belgrade: Strategic Marketing; 2007.

10. Statistical Office of the Republic of Serbia; Strategic Marketing Research Agency. Serbia multiple indicator cluster survey: final report. Belgrade: UNICEF; 2007.

11. Bogdanović D, Nikić D, Petrović B, Kocić B, Jovanović J, Nikolić M, et al. Mortality of Roma population in Serbia, 2002-2005. Croat Med J. 2007 Oct;48(5):720-6.

12. OXFAM. Roma health: final report. Belgrade: Oxfam; 2003.

13. Institute of Public Health of Serbia. Health of population of Serbia: analytical study 1997-2007 [Internet]. Belgrade: Institute of Public Health of Serbia; 2009 [cited 2011 Aug 4]. Available from: http://www.batut.org.rs/ download/publikacije/Health\%20of\%20population\%201997-2007.pdf.

14. Gourgoulianis KI, Tsoutsou P, Fotiadou N, Samaras K, Dakis D, Molyvdas PA. Lung function in Gypsies in Greece. Arch Environ Health. 2000 Nov-Dec;55(6):453-4.

15. Krajcovicova-Kudlackova M, Blazicek P, Spustova V, Valachovicova M, Ginter E. Cardiovascular risk factors in young Gypsy population. Bratisl Lek Listy. 2004;105(7-8):256-9.

16. Petek D, Rotar Pavlic D, Svab I, Lolić D. Attitudes of Roma toward smoking: qualitative study in Slovenia. Croat Med J. 2006 Apr;47(2):344-7. 